\title{
Experimental and numerical study for the post buckling behaviour of plate girders subjected to bending and shear
}

\author{
Wael Shawky ${ }^{*}$, and Ghaidaa Nabil $^{2}$ \\ ${ }^{1}$ University of Technology, Baghdad, Iraq \\ ${ }^{2}$ Ashoor General Constructive Contract Company, Baghdad, Iraq
}

\begin{abstract}
This research offers experimental and numerical study for the ultimate strength analysis and post buckling behaviour of plate girders subjected to shear and bending stresses. Two Plate girders of length $2.5 \mathrm{~m}$ are designed consisting from three separate structural steel plates welded together to form I - section. The dimensions of the first girder section is $512 \mathrm{~mm} \times 120 \mathrm{~mm}$ while the second girder section is $412 \mathrm{~mm} \times$ $120 \mathrm{~mm}$. Mechanical properties for plate girders components were found by testing three samples of each plate. The ultimate shear strength was found by examining two plate girders in the laboratory under concentrated load applied at the middle span. A numerical study of the tested plate girders was carried out by using the software program (ANSYS) to study the behaviour of girders steel under the influence of loads application. The results showed that the ratio of the experimental ultimate load strength to the numerical ultimate load strength is $97 \% 94 \%$ for plate girders 1 and 2 , respectively. For the part of using theoretical study. The results obtained from the equations, it was observed that the ratio of the experimental ultimate load strength to the theoretical ultimate load strength is $83 \%$ for plate girders 1 and $90 \%$ for the plate girder 2. Through comparison between experimental, numerical and theoretical results it was observed good and acceptable agreement. Thus confirming the accuracy of the modelling between this methods and obtain convergent results in all cases. Also it was found when an increase in the depth of the web has effect in increasing the ultimate shear strength for plate girder by about $19 \%$.
\end{abstract}

\section{Introduction}

A girder bridge is likely the most common and most basic bridge. Plate Girders Bridge became popular in the late $19^{\text {th }}$ century, when the plate girders were used for the construction of railroad bridges. In order to obtain plate girders, plates were connected together by rivets and angles. Bolted and riveted plate girders were replaced by using welded plate girders due to their better economy, quality and aesthetics. In general, Modern plate girders are fabricated by welding two steel flanges, a steel web and a series of transverse steel stiffeners. The main function for using the bottom and top steel flange plates is to resist the bending moments by developing axial tensile and compressive stresses from the bending action. Shear stresses will be resisted by the steel webs. The deep and thin steel web is subjected to a large shear force and thus subjected to shear buckling, the shear buckling strength is always depending on plate thickness, aspect ratio, material properties and imperfections. In order to delay shear buckling, it is possible to use a rigid transverse steel stiffeners, they are constructed to limit the extent and separate the buckling regions. Theoretically [1], buckling is caused by a bifurcation in the solution to the equations of static equilibrium. Under an increasing load and at a certain stage, the further loads are able to be resisted in one of two equilibrium states: first is the purely compressed state (with no lateral deviation) while the second is the laterally-deformed state. The buckling is characterized by the sudden lateral failure of a structural member exposed to high compressive stresses, where the ultimate compressive stress that the material can withstand is larger than the compressive stress at the point of failure. As an applied load is increased on a member, such as a column, it will ultimately become large enough to cause the member to become unstable and is said to have buckled. In 1969 Chern and Ostapenko [2] presented a paper for the ultimate strength analysis of the plate girder panels subjected to shear. The method is applicable to homogeneous, hybrid, symmetrical, and unsymmetrical plate girders. The ultimate shear strength was assumed to be equal to the sum of the strengths of the tension field action, the frame action and the beam action. While computing the web plate buckling for the beam action, the web plate was assumed to be simply supported at the stiffeners and fixed at the flanges. The tension field developed by the pattern web after buckling different than those proposed by others. At the same time, the frame action (a panel mechanism with plastic hinges) will be developed by flanges at each corner of the girder panel. A comparison was done with the available 33 test results indicates a more consistent and better accuracy of the proposed method than of the

\footnotetext{
* Corresponding author: waelalmuhsin@yahoo.com
} 
methods suggested by other researchers. In 1971 Rockey, Skaloudb [3] presented a plastic method of design for the plate girder Webs. The method allows for the influence of the rigidity of flange upon the webs post buckled behaviour. The design procedure for the study was based on a the behaviour of 40 plate girders tested by the authors, Results were compared to other available experimental data in the Technical Press. Because the design procedure allows for the influence of flange stiffness upon the shear webs post buckled behaviour and according to authors, the method was more accurate than existing design methods. In 1978 Evans, H.R., Porter, D.M. and Rockey, K.C.[4] presented a method to calculate the collapse load for a steel plate girder loaded in both shear and bending. Authors presented an accurate and quick design method which is capable to predict the failure loads of steel plate girders when loaded in bending, shear or by bending and shear. The design process was applied to a large number of test steel girders. Eighty-eight girders, tested by various researchrs were considered. The result of the study showed that a mean value for the ratio of the predicted failure load to the experimental load is 0.997 while the Standard deviation is 0.064 . The method can be accurately applied for girders reinforced by both transverse and longitudinal stiffeners. In 2005 Carlos Graciano, and Euro Casanova[5] presented a numerical study to predict the ultimate strength of I-steel girder webs under the effect of combined action of patch loading and bending moment. The nonlinear finite element analysis was used to conduct the study. Plastic material behaviour, Initial geometrical imperfections, and large deformation effects were taken into account in the model. Experimental results taken from the literature were used to validate the finite element model. A parametric study was carried out to investigate the influence of the relative location of the stiffener and the magnitude of the bending moment on the ultimate strength to patch loading. In 2007 Hassan H. Abbas, Richard Sause, and Robert G. Driver [6] presented experimental, theoretical, and finite-element analysis results for the linear elastic behavior of corrugated web I-girders under in plane loading. A typical corrugated web steel girder formed by two steel flanges welded to one corrugated steel web. A theoretical method, the fictitious load method, was used as an analytical tool for quantifying flange transverse bending in corrugated web I-girders. For validating the method, four experimental large-scale corrugated web Igirder were used. To get additional insight, the finite element analysis results for the tested girders were presented, it is then compared to both the theoretical and experimental results. In 2008 F. Shahabian T.M. Robert [7] presented a theoretical predictions for the ultimate resistance of slender plate girders subjected to shear loading, based on existing formulas and theories, an interaction formula for the ultimate resistance of slender plate girders subjected to combined shear and bending loading was proposed. Results show satisfactory correlation with the available theories. The proposed interaction equation covers web panel aspect ratios $\left(b_{w} / d_{w}\right)$ from 1 to 2 and slender ratios $\left(d_{w} / t_{w}\right)$ from
150 to 300. In 2008 Donald W. White, and Michael G. Barker[8] a paper to evaluate the accuracy and ease for the use of twelve of the most promising models for the shear resistance of transversely stiffened I-girders. Well established models that are used in civil engineering practice in addition to a number of other recently proposed models also were considered. the paper focuses on the merits and limitations of the alternative models relative to Basler's model. Statistical analyses were conducted on the predictions by using various models and an updated data set from 129 experimental shear tests, samples including 11 horizontally curved and 30 hybrid I- steel girders. The results of the study support the conclusion that the form of Basler's model implemented in 2004 AASHTO LRFD Bridge Design Specifications and 2005 AISC Specification for Structural Steel Buildings gives the best combination of simplicity and accuracy to calculate the shear resistance of transversely stiffened steel I-girders. In 2013 by Dong-Ku Shin Eun-Young Cho and Kyungsik Kim [9] conducted a study for the ultimate flexural strengths of bisymmetric and monosymmetric I-girders subjected to local bend-buckling in webs by nonlinear finite element analysis to include post-buckling behaviours. High performance steel (HPS) was used to fabricate the plate girders. Conventional steel were modelled threedimensionally with thin shell elements and ultimate strength analyses were performed utilizing nonlinear techniques provided by a commercial finite element analysis package program, ABAQUS. The ultimate flexural strengths of girders with various slenderness of web were evaluated from the nonlinear FEA and compared with values predicted by the specifications in AASHTO LRFD and Eurocode 3. In 2016, Young Bong Kwon, and Seung Wan Ryu [10] presented a paper for a series of shear test results of plate girders fabricated by using steel plates with a yield stress of $315 \mathrm{MPa}$ for flanges and $235 \mathrm{MPa}$ for the web. The performance of end web panels and the ultimate shear strength with a single double-sided transverse stiffener at support of plate girders undergoing a significant action of tension field were investigated theoretically and experimentally. According to the results of shear test, post-buckling strength in the shear buckling mode is of a significant effect on the ultimate shear strength of end web panels of plat girders. Based on shear test results, a design shear strength formulae for the direct strength method (DSM) for end web panels of plate girders were presented. According to the results, the DSM shear curves can accurately predict the ultimate shear strength of web panels of steel plate girders showing a significant postbuckling behaviour in the shear buckling mode.

\section{Ultimate plate girder resistance}

When a web panel of a plate girder subjected to shear loading, compressive and tensile stresses are developed as shown in Fig.1. Any additional shear loading is carried by an inclined tensile membrane stress field. When increase in load on the girder, the membrane stresses coupled with buckling stress reach yield. 
Extensive yielding in the web leads to failure of the girder with plastic hinges formed in the flanges. The failure mechanism under bending and shear is similar to that for girders loaded in pure shear only. Thus, failure will occur when the plastic hinges have formed in the flanges, which together with the formation of a yield zone in the web plate, form a plastic mechanism.

Four important additional factors must be taken into account when the effects of bending moment are considered [4].

-The presence of the bending stresses will reduce the buckling stress of the web plate.

-The influence of the bending stresses upon the magnitude of the membrane stresses required to produce yield in the web.

-The influence of load shedding from the web to the flanges as a consequence of buckling.

-The reduction in the plastic moment capacity of the flanges by the axial stresses arising from the bending moment.

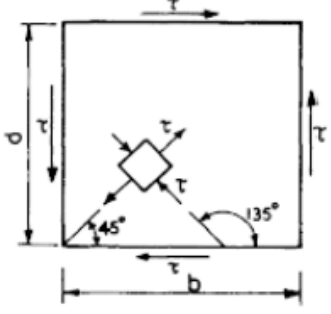

(a) Unbuckled behavior

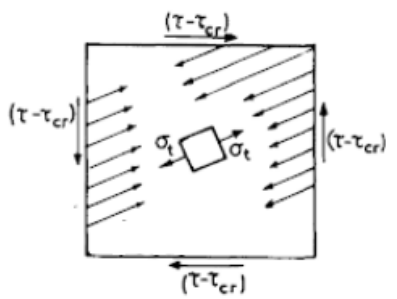

(b) Post buckled behavior

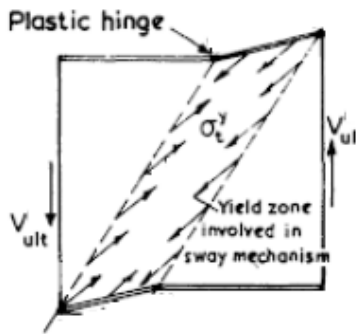

(c) Collapse behaviour

Fig.1. Shear mechanism of web panel

\section{Experimental work}

Two specimens of steel plate girders were designed. The only difference between the two girders is the web depth. Each girder was built up from three plates will act as one unit by welding vertical web plate to the horizontal flange plates(one top and one bottom flange) to form Ishaped section. To increase the strength of the girder it was used transverse and longitudinal stiffeners are welded between the web panel and the flanges from the both sides of the plate girders. Figs. 2 (a, b) and Fig. 3. Show details for the girders.

\subsection{Dimensions of plate girders}

The plate girder dimensions for both samples are listed in Table 1 and Figs. $2(a, b)$. The span of each plate girder is $(2500 \mathrm{~mm})$. The external concentrated load was applied to the specimens at its mid span.
Table 1. Dimensions of plate girders

\begin{tabular}{|l|c|c|c|c|c|}
\hline \multirow{2}{*}{ Sample } & \multicolumn{2}{|c|}{ Flange(mm) } & \multicolumn{3}{c|}{ Web (mm) } \\
\cline { 2 - 6 } & $\begin{array}{c}\mathbf{b f} \\
(\mathbf{m m})\end{array}$ & $\begin{array}{c}\mathbf{t f} \\
(\mathbf{m m})\end{array}$ & $\begin{array}{c}\mathbf{d w} \\
(\mathbf{m m})\end{array}$ & $\begin{array}{c}\mathbf{t w} \\
(\mathbf{m m})\end{array}$ & $\begin{array}{c}\text { Stiffeners spacing } \\
(\mathbf{m m})\end{array}$ \\
\hline Girder 1 & 120 & 6 & 500 & 2 & 575 \\
\hline Girder 2 & 120 & 6 & 400 & 2 & 575 \\
\hline
\end{tabular}

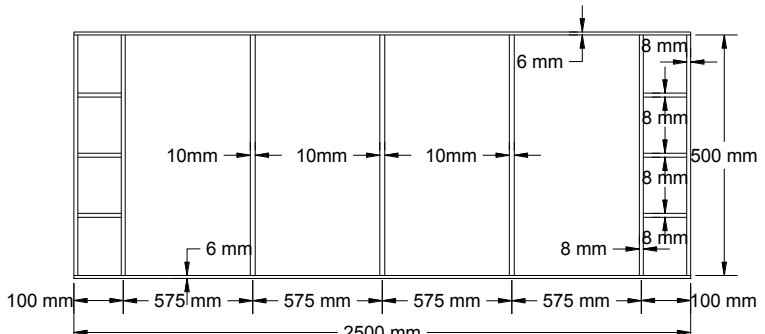

(a)

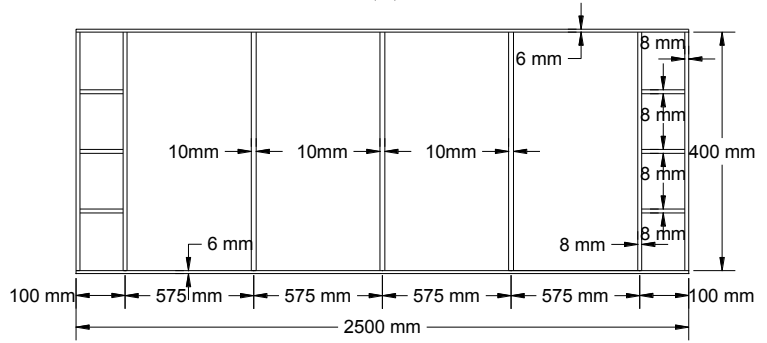

(b)

Fig.2. Plate girder dimensions, (a)- girder 1, (b)- girder 2

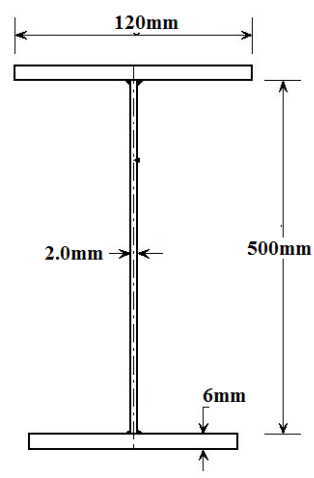

Girder(1)

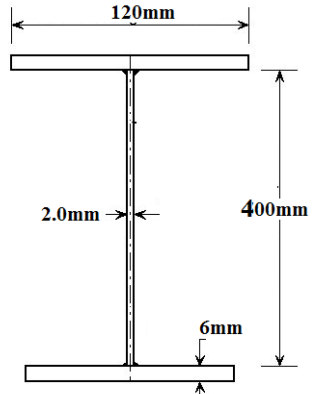

Girder (2)
Fig. 3. The geometry of the tested girders

\subsection{Steel properties}

Six steel tensile specimens were used to test the mechanical properties for the $(6 \mathrm{~mm})$ thickness flange steel plate and for $(2 \mathrm{~mm})$ thickness of web steel. Tensile tests of the steel were carried out according to (ISO6892).The detailed mechanical properties are summarized in Table 2

Table 2. Mechanical properties of the girders

\begin{tabular}{|c|c|c|c|c|c|}
\hline \multirow{4}{*}{$\begin{array}{c}\text { Component } \\
\text { Flange }\end{array}$} & \multirow{4}{*}{$\begin{array}{c}\text { Thickness } \\
\text { (mm) } \\
6\end{array}$} & \multicolumn{2}{|c|}{$\begin{array}{c}\text { Yield stress } \\
\sigma_{y} \\
(\mathrm{MPa})\end{array}$} & \multicolumn{2}{|c|}{$\begin{array}{l}\text { Ultimate tensile } \\
\text { strength } \sigma_{u} \\
\text { (MPa) }\end{array}$} \\
\hline & & 171 & & 286 & \\
\hline & & 197 & 181 & 311 & 296 \\
\hline & & 175 & & 290 & \\
\hline \multirow{3}{*}{ Web } & \multirow{3}{*}{2} & 426 & \multirow{3}{*}{423} & 558 & \multirow{3}{*}{553} \\
\hline & & 458 & & 581 & \\
\hline & & 385 & & 520 & \\
\hline
\end{tabular}




\subsection{Test setup and equipment}

Tests for to two girders was carried out using a testing machine "AVERY" at the structural laboratory in the University of Technology. The maximum load capacity of the machine is $(1500 \mathrm{KN})$. The testing machine is shown in Plate 1, load can be applied by hydraulic pressure. The I-section girders were placed on a horizontal base of the simply supported and the load was applied to the mid-span of the plate girders, were tested under concentrated load. The applied load is automatically shown on a large dial contained in the indicator cabinet of the testing machine. The deflections for two girders were measured using dial gauge of $0.01 \mathrm{~mm}$ increments. The dial gauge was installed under the bottom flange at the mid-span of girder. The deflection was read at every increment of load of $10 \mathrm{KN}$ for girder 1 and $5 \mathrm{KN}$ for girder 2. The test was terminated when the girders had shown collapse and large deformation had occurred at the web panel and flanges without any ability for the load to increase. After the girders had failure, the load was removed.

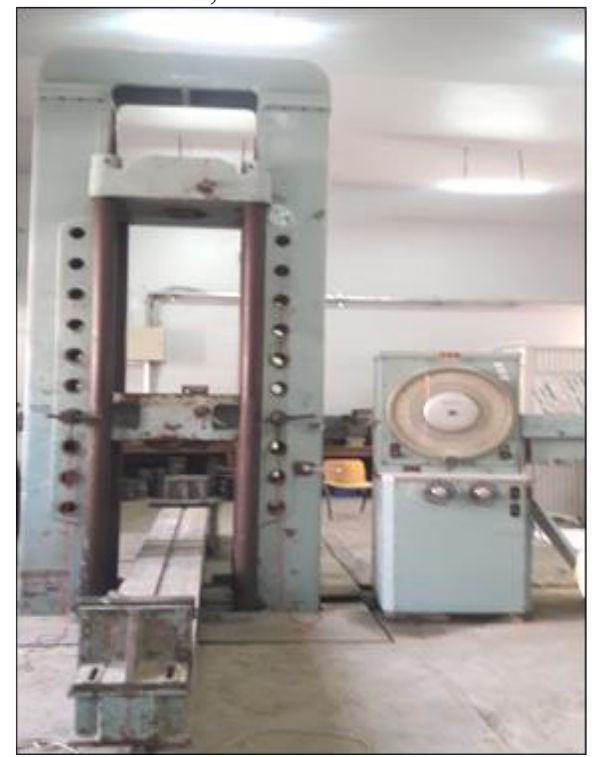

Plate 1. Testing machine

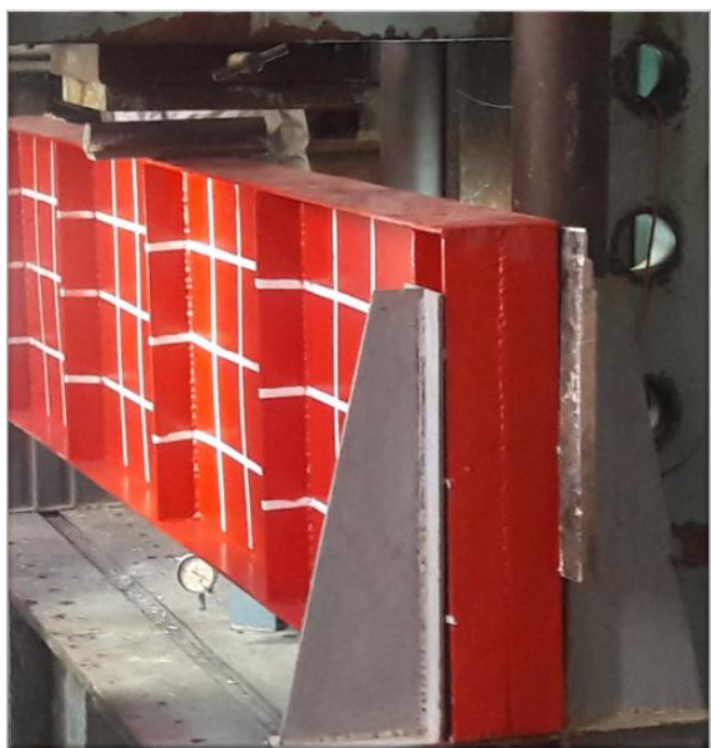

Plate 2. Test Setup

\subsection{Experimental results}

The two plate girders were examined by applying load gradually until reaching failure. The ultimate load value for the first girder is $(175 \mathrm{KN})$ while the second girder is $(146 \mathrm{KN})$. The post buckling and failure of each plate girders are shown in Plates 3 and plate 4. The loaddeflection curves for the girders are presented in Fig.4. The relationship was approximately linear in the major part of the loading, and then the curve starts to bend slightly due to the occurrence of deformation in the web panel of the girder. All stages of the steel girders deformations were noted, first, the web buckled, then plastic hinges form on the flanges.

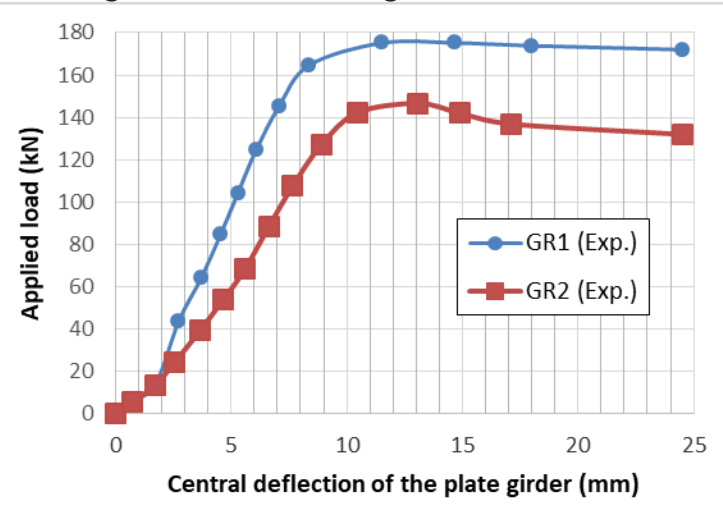

Fig.4 Comparison load-deflection curve between girders 1 and 2 


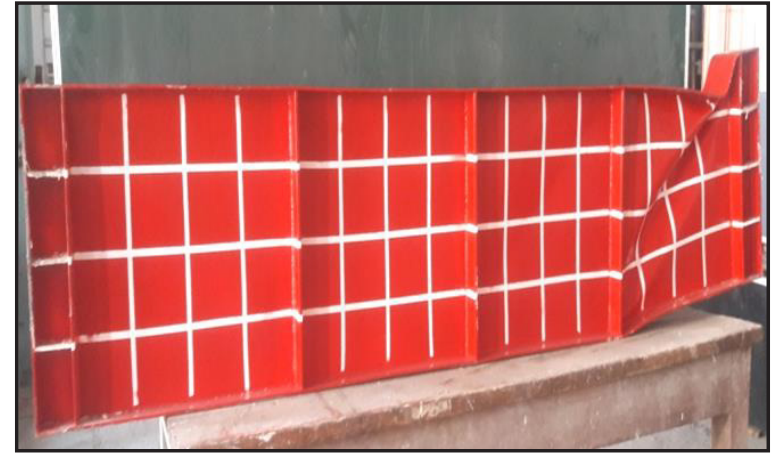

Plate 3. Post buckling deformation for Girder 1

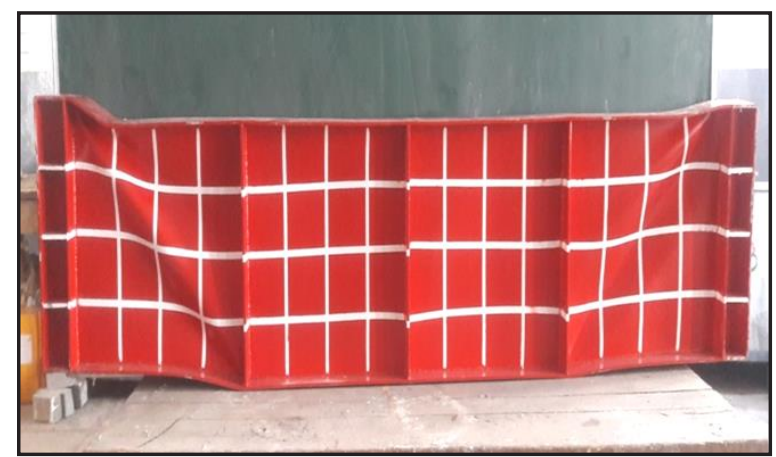

Plate 4. Post buckling deformation for Girder 2

\subsection{Numerical results}

The finite element analysis software ANSYS is used to perform the numerical part of the study. The two steel plate girders loaded in shear and bending were analysed. In order to build the model of the girders, the shell elements 43 from the code element library was adopted. Perfectly elastoplastic behaviour for the material was considered. Poisson's ratio was set to $v=0.3$. The method of solving an Eigen value problem was used to obtain the value of $\mathrm{t}$ cr whereas $\mathrm{V}$ ult was obtained by using the inelastic buckling analysis. The inelastic buckling analysis is essentially nonlinear static analysis that incorporates both material and geometrical nonlinearities with the assumption of an elastic-perfectly plastic constitutive relation. The Von-Mises yield criterion was employed to account for material nonlinearity. To initiate out-of-plane deformations, and since the out-of-plane deformations cannot occur for a perfect flat plate, an initial imperfection was applied to the plate girders having the same shape of the first buckling mode. The results showed that the ultimate load value for the first girder is $(180 \mathrm{kN})$ while the second girder is $(155.26 \mathrm{kN})$. The deflection and failure results of each plate girder are shown in Figs.5, 6 and 7.

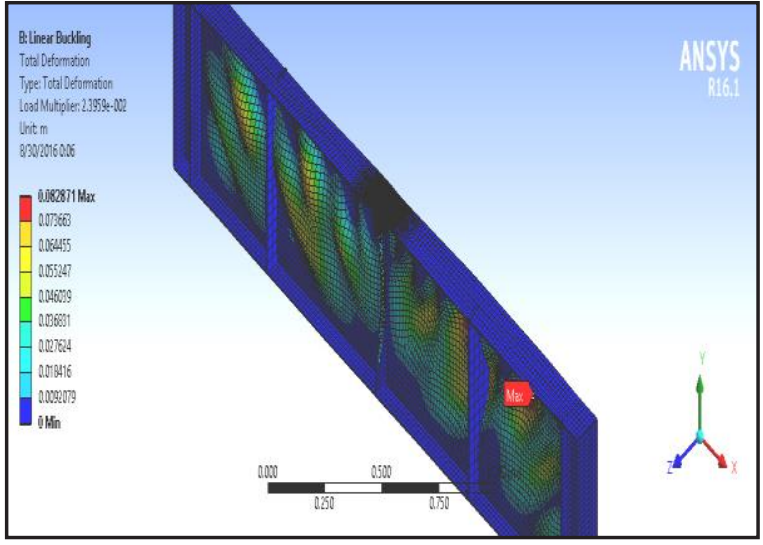

Fig.5. Plate girder 1
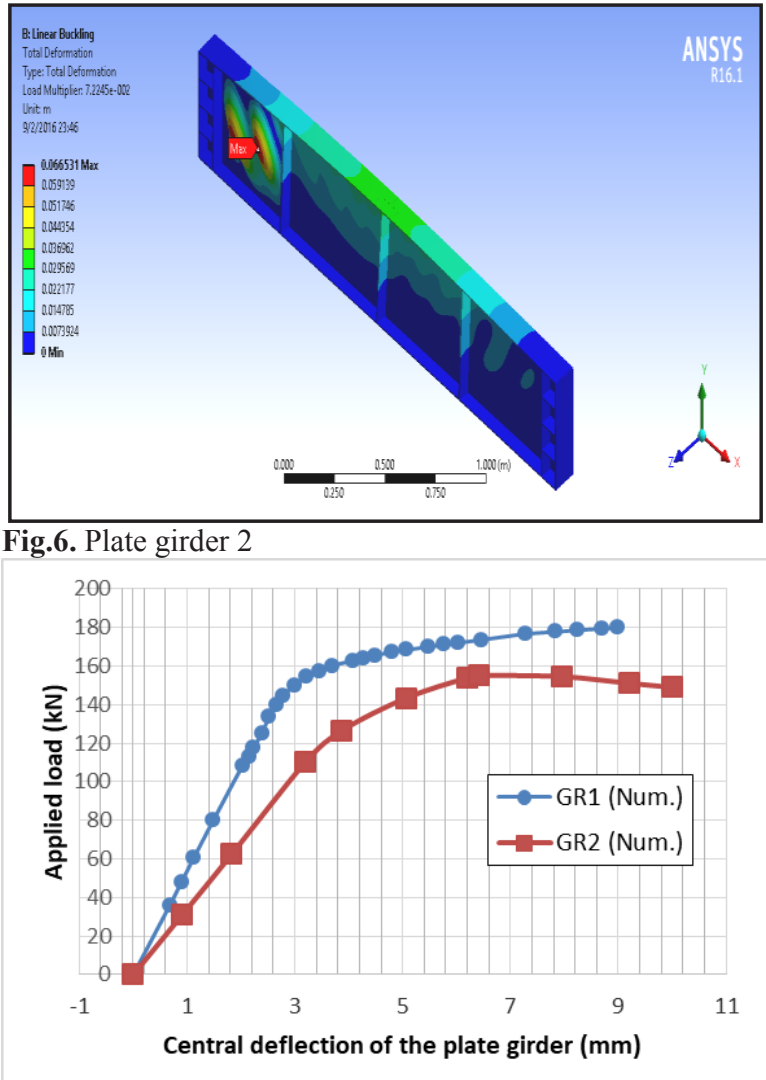

Fig.7. Load-deflection curve for girder 1

\subsection{Theoretical equation results}

The theoretical equations derived by Porter et al.[11] were used to calculate the ultimate shear strength for the two plate girders. Mechanical properties of the steel plates shown in table 2 were used. An average yield stress $\left(\sigma_{y w}^{\prime}\right)$ for web is $423 \mathrm{MPa}$ and an average yield stress $\left(o_{y f}^{\prime}\right)$ for flange is $181 \mathrm{MPa}$ were used. Results are listed in Table 4.

Table 3. Mechanical properties of the girders

\begin{tabular}{|c|c|c|}
\hline Girder & $\begin{array}{c}\text { Depth of the } \\
\text { Girder }(\mathbf{m m})\end{array}$ & $\begin{array}{c}\mathbf{2} \mathbf{V}_{\text {ult }} \\
\mathbf{k N}\end{array}$ \\
\hline GR 1 & 500 & 210.9 \\
\hline GR 2 & 400 & 162.13 \\
\hline
\end{tabular}

\section{Discussion}


Two different comparisons were conducted, the first was between the results obtained from experimental work $\left(\mathrm{V}_{\text {EXP }}\right)$ and numerical study $\left(\mathrm{V}_{\mathrm{ANS}}\right)$. The second was with the ultimate shear load results which obtained from theoretical equations $\left(2 \mathrm{~V}_{\mathrm{ult}}\right)$. Results are listed in Table 4.

Table 4. Comparison between experimental, numerical and theoretical equation results.

\begin{tabular}{|c|c|c|c|c|c|}
\hline Models & $\begin{array}{l}\mathbf{V}_{\text {EXP }} \\
(\mathbf{K N})\end{array}$ & $\begin{array}{l}\mathbf{V}_{\text {ANS }} \\
(\mathbf{K N})\end{array}$ & $\begin{array}{l}\mathbf{V}_{\text {EXP }} / \\
\mathbf{V}_{\text {ANS }}\end{array}$ & $\begin{array}{l}\mathbf{2} \mathbf{V}_{\text {ult }} \\
(\mathbf{K N})\end{array}$ & $\begin{array}{l}\mathbf{V}_{\text {EXP }} / \\
\mathbf{2 V}_{\text {ult }}\end{array}$ \\
\hline GR 1 & 175 & 180 & 0.972 & 210.9 & 0.83 \\
\hline GR 2 & 146 & 155.26 & 0.94 & 162.13 & 0.90 \\
\hline
\end{tabular}

From this comparison (comparable in both cases) it can be observed the ratio $\mathrm{V}_{\text {EXP }} / \mathrm{V}_{\mathrm{ANS}}$ show reasonable agreement within $(6 \%)$. While the ratio $\mathrm{V}_{\text {EXP }} / 2 \mathrm{~V}_{\text {ult }}$ refers to the approximation in the experimental and theoretical results within (17\%). Equations used for the theoretical part of the study was derived for shear only while the study was based on shear and bending, therefore some differences have appeared.

\section{Conclusions}

Two plate girders were tested until failure considering the combined effect of shear and bending for studying the behaviour of the ultimate shear strength and buckling. Conclusions based on the experimental, numerical and theoretical equations results were obtained. The results showed that the ultimate shear strength of web panel can be affected significantly by the size of the web and the span/depth ratio. The samples were capable of simulating the behaviour of the web panel and provided very good results. Theoretical study depend on the equations proposed by previous researchers shows an acceptable accuracy. In general, there are acceptable and good agreement between the results that have been obtained from the experimental, numerical and theoretical study.

The ANSYS model was used to perform a study for investigating the effect of geometrical and mechanical properties on the ultimate resistance of the plate girder. Experimental works confirm the general equations that are used for calculating the failure load in the plate girders and confirms the ANSYS model results. As a conclusion, the increase in the web depth form $400 \mathrm{~mm}$ to $500 \mathrm{~mm}$ will give an increase in the ultimate load failure by approximately $19 \%$.

\section{References}

1. J. Newman, Physics Of The Life Sciences (Springer, New York, 2008).

2. C. Chern, A. Ostapenko, Fritz Laboratory Reports. Paper 264 (1969).

3. K.C. Rockey, M Skaloud, The Structural Engineer, 50, 313 (1972).
4. H. R Evans, D.M. Porter, K.C. Rockey, IABSE Proceedings (1978).

5. C. Graciano, E. Casanova E., Journal of Constructional Steel Research,61(1), 93 (2005).

6. H. Abbas, R. Sause, R. Driver, Engineering Structures, 29(11), 2816 (2007).

7. F. Shahabian, T.M. Roberts, Scientia Iranica, Sharif University of Technology, 15(1), 16 (2008) .

8. D.W. White, M.G. Barker, J. Struct. Eng., 134(9), 1425 (2008).

9. K.S. Dong, Y.C. Eun, K. Kyungsik, International Journal of Steel Structures, 13(2), 291 (2013)

10. Y.B. Kwona, and S.W. Ryu, Thin-Walled Structures, 98(B), 578 (2016).

11. D.M. Porter, K.C. Rockey, H.R. Evans, The Structural Engineer, 53(8), 313 (1975). 